\title{
Does the microendoscopic technique reduce mortality and major complications in patients undergoing lumbar discectomy? A propensity score-matched analysis using a nationwide administrative database
}

\author{
Junichi Ohya, MD, ${ }^{1}$ Yasushi Oshima, MD, PhD, ${ }^{1}$ Hirotaka Chikuda, MD, PhD, ${ }^{1}$ Takeshi Oichi, MD, ${ }^{1}$ \\ Hiroki Matsui, MPH, ${ }^{2}$ Kiyohide Fushimi, MD, PhD, ${ }^{3}$ Sakae Tanaka, MD, PhD, ${ }^{1}$ and \\ Hideo Yasunaga, MD, $\mathrm{PhD}^{2}$
}

Departments of ${ }^{1}$ Orthopaedic Surgery and ${ }^{2}$ Clinical Epidemiology and Health Economics, School of Public Health, The University of Tokyo; and ${ }^{3}$ Department of Health Policy and Informatics, Tokyo Medical and Dental University Graduate School of Medicine, Tokyo, Japan

\begin{abstract}
OBJECTIVE Although minimally invasive spinal surgery has recently gained popularity, few nationwide studies have compared the adverse events that occur during endoscopic versus open spinal surgery. The purpose of this study was to compare perioperative complications associated with microendoscopic discectomy (MED) and open discectomy for patients with lumbar disc herniation.
\end{abstract}

METHODS The authors retrospectively extracted from the Diagnosis Procedure Combination database, a national inpatient database in Japan, data for patients admitted between July 2010 and March 2013. Patients who underwent lumbar discectomy without fusion surgery were included in the analysis, and those with an urgent admission were excluded. The authors examined patient age, sex, Charlson Comorbidity Index, body mass index, smoking status, blood transfusion, duration of anesthesia, type of hospital, and hospital volume (number of patients undergoing discectomy at each hospital). One-to-one propensity score matching between the MED and open discectomy groups was performed to compare the proportions of in-hospital deaths, surgical site infections (SSIs), and major complications, including stroke, acute coronary events, pulmonary embolism, respiratory complications, urinary tract infection, and sepsis. The authors also compared the hospital length of stay between the 2 groups.

RESULTS A total of 26,612 patients were identified in the database. The mean age was 49.6 years (SD 17.7 years). Among all patients, 17,406 (65.4\%) were male and $6422(24.1 \%)$ underwent MED. A propensity score-matched analysis with 6040 pairs of patients showed significant decreases in the occurrence of major complications $(0.8 \%$ vs $1.3 \%, p=$ $0.01)$ and SSI ( $0.1 \%$ vs $0.2 \%, p=0.02)$ in patients treated with MED compared with those who underwent open discectomy. Overall, MED was associated with significantly lower risks of major complications $(\mathrm{OR} 0.62,95 \% \mathrm{Cl} 0.43-0.89, \mathrm{p}=$ 0.01 ) and $\mathrm{SSI}(\mathrm{OR} 0.29,95 \% \mathrm{CI} 0.09-0.87, \mathrm{p}=0.03)$ than open discectomy. There was a significant difference in length of hospital stay ( 11 vs 15 days, $p<0.001$ ) between the groups. There was no significant difference in in-hospital mortality between MED and open discectomy.

CONCLUSIONS The microendoscopic technique was associated with lower risks for SSI and major complications following discectomy in patients with lumbar disc herniation.

http://thejns.org/doi/abs/10.3171/2015.10.FOCUS15479

KEY WORDS lumbar disc herniation; minimally invasive surgery; endoscopic surgery; mortality; complication; surgical site infection 
$\mathrm{E}$ NDOSCOPIC spinal surgery was developed as a minimally invasive spinal surgery. Microendoscopic discectomy (MED) was originally developed in 1997 for the treatment of lumbar disc herniation, ${ }^{9}$ and since then, microendoscopic surgery techniques have been used for the treatment of several spinal disorders, including foraminal stenosis and disorders at the level of the spinal cord (i.e., cervical and thoracic spine), with favorable outcomes. ${ }^{2,10,15,19,21,22,25,41}$ Several studies have demonstrated that endoscopic discectomy is associated with less invasiveness than open discectomy, with comparable clinical outcomes. ${ }^{11-14,30,32-35,37}$ However, because these studies involved small numbers of patients in single institutions, it remains unclear whether MED is truly a safer technique than open discectomy. Despite the clinical importance of understanding the risk for adverse surgical comorbidities, few nationwide studies have examined these issues by directly comparing MED and open discectomy. The purpose of this study was to compare the mortality and morbidities in patients with lumbar disc herniation who had been treated using MED and open discectomy based on a propensity score-matched analysis of data obtained from a nationwide administrative database in Japan.

\section{Methods}

\section{Data Source}

We used data abstracted from the Japanese Diagnosis Procedure Combination (DPC) database, the details of which have been described previously. ${ }^{4-7,17,24}$ Briefly, the database includes administrative claims data and discharge abstract data from approximately 1000 hospitals across Japan. All 82 academic hospitals are obliged to contribute to the database, but the participation of community hospitals is voluntary. Approximately $50 \%$ of all acute-care inpatients in Japan were included in the DPC database in 2011. The database includes the following information: patient age and sex; main diagnoses; surgical procedures; comorbidities that were already present at admission and complications that occurred after admission, recorded using International Classification of Diseases, 10th Revision (ICD-10) codes; length of stay; and in-hospital death. Surgical procedures are coded using original Japanese codes. The DPC database clearly differentiates between preoperative comorbidities and postoperative complications. Informed patient consent for inclusion in this study was waived because of the anonymous nature of the data. The study was approved by the institutional review board of The University of Tokyo.

\section{Patient Selection and Data}

We extracted from the database data for patients admitted between July 2010 and March 2013. We included patients who underwent lumbar discectomy without fusion surgery. Patients requiring urgent admission were excluded. Patients who underwent surgery under local anesthesia were also excluded. The following details were examined: patient age and sex; body mass index (BMI); smoking status; Charlson Comorbidity Index (CCI); blood transfusion; duration of anesthesia; type of hospital (academic or nonacademic); and hospital volume (average annual num- ber of patients undergoing discectomy at each hospital). The CCI can quantify the prognosis of patients enrolled in a large cohort and is widely used to measure case-mix administrative data. The index is based on a point-scoring system (from 0 to 40 ) for the presence of specific associated diseases. Quan and colleagues ${ }^{29}$ have provided a validated chart showing how individual comorbidities correspond to a set of ICD-10 codes. Based on their protocol, each ICD-10 code associated with a comorbidity was converted into a score, and the scores were summed for each patient to determine the CCI.

\section{Outcomes}

The clinical outcomes evaluated were in-hospital death, major complications, and surgical site infection (SSI). Major complications included stroke (ICD-10 codes I60-I64), acute coronary events (I21-I24), pulmonary embolism (I26), respiratory complications (pneumonia [J12J18], postoperative respiratory disorders [J95], or respiratory failure [J96]), urinary tract infection (J95), acute renal failure (N17), and sepsis (A40, A41).

In this study, SSI was defined as cases that were coded as SSI (T813, T814) and required additional surgical intervention following the index discectomy.

\section{Statistical Analysis}

To describe the patient demographic data, categorical variables were summarized as the number and proportion, and continuous variables were summarized as the mean and standard deviation (SD). We compared patient demographic data between the MED and open discectomy groups in the unmatched and propensity score-matched groups using the standardized difference. An absolute standardized difference $>0.1$ was considered to indicate significant imbalance of a baseline covariate. ${ }^{1}$

\section{Propensity Score Matching}

To adjust for measured confounding factors, we performed propensity score matching. ${ }^{8}$ To estimate propensity scores, we fitted a logistic regression model for the receipt of MED as a function of patient demographic and hospital factors, including patient age, sex, CCI, BMI, smoking status, duration of anesthesia, blood transfusion, type of hospital, and hospital volume. The C-statistic for evaluating the goodness of fit was calculated. Each patient in the MED group was matched with a patient in the open discectomy group with the closest estimated propensity score within a specified range $(\leq 0.2$ of the pooled SD of the estimated logits) using the nearest-neighbor method without replacement.

Fisher's exact test was used to compare the proportions of SSI, at least 1 major complication, and in-hospital death between the propensity-matched pairs of the MED and discectomy groups. The Mann-Whitney U-test was used to compare the median length of hospital stay between the propensity-matched pairs. Univariate logistic regression analysis for the propensity-matched population was performed to estimate the odds ratio (OR) and 95\% confidence interval (CI) of the MED group with reference to the open discectomy group for SSI and at least 1 major 
complication. The threshold for significance was set at $\mathrm{p}$ $<0.05$. All statistical analyses were conducted using SPSS version 20.0 (IBM Corp.).

\section{Results}

A total of 26,612 patients were identified in the database. The mean age was 49.6 years (SD 17.7 years), and 17,406 patients $(65.4 \%)$ were male. The median length of hospital stay was 15 days (IQR 11-20 days). Among all patients, 6422 patients $(24.1 \%)$ underwent MED and 20,190 patients $(75.9 \%)$ underwent open discectomy. By one-toone propensity score matching, 6040 pairs were selected. The C-statistic for goodness of fit was 0.683 .
Table 1 shows the patient demographic data in the unmatched and propensity score-matched groups. In the unmatched group, patients with a younger age, lower CCI, treatment in an academic hospital, and admission to a high-volume hospital were more likely to undergo MED. After propensity score matching, the distributions of the patient backgrounds were closely balanced between the MED group and the open discectomy group.

Table 2 shows the proportions of in-hospital death, at least 1 major complication, SSI, and median length of stay in the unmatched and propensity score-matched groups. Fisher's exact test for the propensity score-matched groups showed no significant difference for in-hospital mortality

TABLE 1. Demographic data in the unmatched and propensity score-matched groups

\begin{tabular}{|c|c|c|c|c|c|c|}
\hline \multirow[b]{2}{*}{ Parameter } & \multicolumn{3}{|c|}{ Unmatched Group } & \multicolumn{3}{|c|}{ Propensity Score-Matched Group } \\
\hline & MED & $\begin{array}{c}\text { Open } \\
\text { Discectomy }\end{array}$ & $\begin{array}{l}\text { Standardized } \\
\text { Difference* }^{*}\end{array}$ & MED & $\begin{array}{c}\text { Open } \\
\text { Discectomy }\end{array}$ & $\begin{array}{l}\text { Standardized } \\
\text { Difference* }^{*}\end{array}$ \\
\hline No. of patients & 6422 & 20,190 & & 6040 & 6040 & \\
\hline Male sex (\%) & $4218(65.7)$ & $13,188(65.3)$ & 0.01 & $3941(65.2)$ & $3919(64.9)$ & 0.01 \\
\hline \multicolumn{7}{|l|}{ Patient age in yrs (\%) } \\
\hline$\leq 29$ & $1179(18.4)$ & $2619(13.0)$ & 0.15 & $1060(17.5)$ & $1151(19.1)$ & -0.00 \\
\hline $30-39$ & $1430(22.3)$ & $3771(18.7)$ & 0.09 & $1315(21.8)$ & $1328(22.0)$ & -0.01 \\
\hline $40-49$ & $1222(19.0)$ & $3428(17.0)$ & 0.05 & $1138(18.8)$ & $1153(19.1)$ & -0.01 \\
\hline $50-59$ & $931(14.5)$ & $3110(15.4)$ & -0.03 & $905(15.0)$ & $874(14.5)$ & 0.01 \\
\hline $60-69$ & $941(14.7)$ & $3730(18.5)$ & -0.10 & $914(15.1)$ & $886(14.7)$ & 0.01 \\
\hline$\geq 70$ & $719(11.2)$ & $3532(17.5)$ & -0.18 & $708(11.7)$ & $648(10.7)$ & 0.03 \\
\hline \multicolumn{7}{|l|}{$\mathrm{CCl}(\%)$} \\
\hline 0 & $6048(94.2)$ & $18,308(90.7)$ & 0.13 & $5672(93.9)$ & $5681(94.1)$ & -0.01 \\
\hline 1 & $166(2.6)$ & $746(3.7)$ & -0.06 & $164(2.7)$ & $177(2.9)$ & -0.01 \\
\hline$\geq 2$ & $208(3.2)$ & $1136(5.6)$ & -0.12 & $204(3.4)$ & $182(3.0)$ & 0.02 \\
\hline \multicolumn{7}{|l|}{$\mathrm{BMI}$ in $\mathrm{kg} / \mathrm{m}^{2}(\%)$} \\
\hline$<18.5$ & $320(5.0)$ & $987(4.9)$ & 0.00 & $300(5.0)$ & $303(5.0)$ & 0.00 \\
\hline $18.5-23$ & $2622(40.8)$ & $8001(39.6)$ & 0.02 & $2433(40.3)$ & $2431(40.2)$ & 0.00 \\
\hline $23-25$ & $1403(21.8)$ & $4312(21.4)$ & 0.01 & $1313(21.7)$ & $1289(21.3)$ & 0.01 \\
\hline $25-30$ & $1575(24.5)$ & $5272(26.1)$ & -0.04 & $1510(25.0)$ & $1520(25.2)$ & -0.01 \\
\hline$>30$ & $413(6.4)$ & $1323(6.6)$ & -0.01 & $395(6.5)$ & $408(6.8)$ & -0.01 \\
\hline Unknown (\%) & $89(1.4)$ & $295(1.5)$ & -0.01 & $89(1.5)$ & $89(1.5)$ & 0.00 \\
\hline \multicolumn{7}{|l|}{ Smoking status (\%) } \\
\hline Smoker & $2325(36.2)$ & $7470(37.0)$ & 0.02 & $2164(35.8)$ & $2075(34.4)$ & 0.03 \\
\hline Nonsmoker & $3497(54.5)$ & $10,880(53.9)$ & 0.01 & $3280(54.3)$ & $3347(55.4)$ & -0.02 \\
\hline Data missing/unknown & $600(9.3)$ & $1840(9.1)$ & 0.01 & $596(9.9)$ & $618(10.2)$ & -0.01 \\
\hline Blood transfusion (\%) & $12(0.2)$ & $100(0.5)$ & -0.05 & $12(0.2)$ & $13(0.2)$ & 0.00 \\
\hline \multicolumn{7}{|c|}{ Duration of anesthesia in $\min (\%) \dagger$} \\
\hline$\leq 120$ & $1570(24.8)$ & $5583(28.2)$ & -0.08 & $1337(22.5)$ & $1246(20.8)$ & 0.04 \\
\hline $121-180$ & $2801(44.3)$ & 8541 (43.2) & 0.02 & $2680(45.1)$ & $2649(44.3)$ & 0.02 \\
\hline $181-240$ & $1395(22.1)$ & $3761(19.0)$ & 0.08 & $1373(23.1)$ & $1494(25.0)$ & -0.04 \\
\hline $241-300$ & $400(6.3)$ & $1231(6.2)$ & 0.00 & $394(6.6)$ & $424(7.1)$ & -0.02 \\
\hline $301-360$ & $97(1.5)$ & $382(1.9)$ & -0.03 & $97(1.6)$ & $107(1.8)$ & -0.02 \\
\hline$\geq 361$ & $61(1.0)$ & $272(1.4)$ & -0.04 & $61(1.0)$ & $63(1.1)$ & -0.01 \\
\hline Teaching hospital (\%) & $1179(18.4)$ & $2854(14.1)$ & 0.12 & $1176(19.5)$ & $1285(21.3)$ & -0.04 \\
\hline Hospital vol (no./yr [SD]) & $69.1(64.0)$ & $41.7(48.6)$ & 0.48 & $59.1(50.7)$ & $55.2(59.3)$ & 0.07 \\
\hline
\end{tabular}

* An absolute standardized difference of $>0.1$ indicates significant imbalance of a baseline covariate.

$\dagger$ Data were missing for some patients: 6324 for the unmatched MED group and 19,770 for the unmatched open discectomy group. 
TABLE 2. Rates of in-hospital death, major complications, SSI, and length of stay in the unmatched and propensity score-matched groups

\begin{tabular}{|c|c|c|c|c|c|c|}
\hline \multirow[b]{2}{*}{ Parameter } & \multicolumn{2}{|c|}{ Unmatched Group (no. [\%]) } & \multirow[b]{2}{*}{ p Value } & \multicolumn{2}{|c|}{ Propensity Score-Matched Group (no. [\%]) } & \multirow[b]{2}{*}{$p$ Value } \\
\hline & MED & Open Discectomy & & MED & Open Discectomy & \\
\hline No. of patients & 6422 & 20,190 & & 6040 & 6040 & \\
\hline In-hospital death & $1(0.0)$ & $9(0.0)$ & 0.47 & $1(0.0)$ & $1(0.0)$ & 1.00 \\
\hline At least 1 major complication & $48(0.7)$ & $314(1.6)$ & $<0.001$ & $47(0.8)$ & $76(1.3)$ & 0.009 \\
\hline Stroke & $4(0.1)$ & $15(0.1)$ & 1.00 & $3(0.0)$ & $0(0.0)$ & 0.25 \\
\hline Acute coronary events & $28(0.4)$ & $169(0.8)$ & 0.001 & $28(0.5)$ & $40(0.7)$ & 0.14 \\
\hline Pulmonary embolism & $0(0.0)$ & $3(0.0)$ & 1.00 & $0(0.0)$ & $1(0.0)$ & 1.00 \\
\hline Respiratory complications & $5(0.1)$ & $35(0.2)$ & 0.10 & $5(0.1)$ & $6(0.1)$ & 1.00 \\
\hline Urinary tract infection & $8(0.1)$ & $79(0.4)$ & 0.001 & $8(0.1)$ & $23(0.4)$ & 0.01 \\
\hline Sepsis & $1(0.0)$ & $7(0.0)$ & 0.69 & $1(0.0)$ & $2(0.0)$ & 1.00 \\
\hline SSI & $4(0.1)$ & $53(0.3)$ & 0.003 & $4(0.1)$ & $14(0.2)$ & 0.02 \\
\hline Median length of stay in days & 11 & 16 & $<0.001$ & 11 & 15 & $<0.001$ \\
\hline
\end{tabular}

between the MED and open discectomy groups $(0.0 \%$ vs $0.0 \%, \mathrm{p}=1.00)$. Patients in the MED group exhibited a significantly lower risk of major complications $(0.8 \%$ vs $1.3 \%$, $\mathrm{p}=0.01)$ and SSI $(0.1 \%$ vs $0.2 \%, \mathrm{p}=0.02)$ than patients in the open discectomy group. There was a significant difference in the median length of stay (11 vs 15 days for MED and open discectomy, respectively, $\mathrm{p}<0.001)$ between the 2 groups.

Table 3 shows the results of logistic regression analysis for the occurrence of major complications and SSI. The MED group was significantly less likely to have major complications (OR 0.62, 95\% CI 0.43-0.89, p = 0.01) and SSI (OR 0.29, 95\% CI 0.09-0.87, p = 0.03) than the open discectomy group.

\section{Discussion}

The main finding of this study was that patients treated using MED experienced lower rates of postoperative SSI and major complications than patients treated with open discectomy, even after adjustment for the measured confounders using propensity score matching. The analysis of a nationwide database enabled us to investigate a large number of samples and to evaluate the magnitude and impact of surgical techniques on major postoperative complications.

Microendoscopic surgery for lumbar disc herniation was developed with the concept of preserving posterior elements (i.e., paraspinal muscles) as much as possible. Several previous randomized control studies comparing MED with open surgery have shown favorable postoperative outcomes following MED. ${ }^{11,12,14,30,32,33,39}$ Although surgical skills, such as hand-eye coordination, are required, MED could become the standard surgical treatment method for patients with lumbar disc herniation. However, previous reports were insufficient to conclude that MED shows superiority in terms of postoperative complications as compared with open discectomy because of the small sample sizes involved.

MED was thought to be a safer and less invasive surgical technique than open discectomy. Previous reports have shown that patients undergoing MED experience fewer indicators of surgical invasiveness than those undergoing open discectomy. ${ }^{13,23,34,35,36,40}$ Markers of invasiveness include postoperative elevations in serum levels of inflammatory markers and muscle enzymes, , $^{13,34,36}$ irritation of nerve roots using intraoperative neuromonitoring, ${ }^{35,40}$ and muscle damage by axial MRI. ${ }^{23}$ However, if postoperative complications often occurred, it would be concluded that endoscopic surgery is no longer a safe procedure, despite its lower invasiveness. Matsumoto and colleagues ${ }^{18}$ reported the complication rates for endoscopic spinal surgery in a nationwide retrospective study. In their series, which included discectomy, laminectomy, fenestration, and fusion surgery, the incidence of surgery-related complications (e.g., dural injury) was $2.1 \%$. One advantage of the present study was the study design using open discectomy as a comparable reference. Another advantage was including treated patients from multiple calendar years, while the study by Matsumoto and colleagues only evaluated patients treated in 2007. To the best of our knowledge, the present study is the first to compare postoperative complications between MED and open discectomy procedures for the treatment of lumbar disc herniation while adjusting for patient characteristics using propensity score matching. Our results suggest that the microendoscopic technique is safer and less invasive for the treatment of patients

TABLE 3. Logistic regression analyses for the occurrence of major complications and SSI in the propensity score-matched group

\begin{tabular}{|c|c|c|c|c|c|c|}
\hline \multirow[b]{2}{*}{ Procedure } & \multicolumn{3}{|c|}{ At Least 1 Major Complication } & \multicolumn{3}{|c|}{ SSI } \\
\hline & OR & $95 \% \mathrm{Cl}$ & p Value & OR & $95 \% \mathrm{Cl}$ & p Value \\
\hline Open discectomy & Reference & & & Reference & & \\
\hline MED & 0.62 & $0.43-0.89$ & 0.009 & 0.29 & $0.09-0.87$ & 0.03 \\
\hline
\end{tabular}


with lumbar disc herniation, as demonstrated by a lower risk of SSI and major complications.

Data in the present study are consistent with those in previous reports evaluating minimally invasive techniques..$^{20,26,28,38}$ In a retrospective study using an administrative database, McGirt and colleagues ${ }^{20}$ reported that their minimally invasive technique was associated with a decrease in the incidence of SSI following 2-level posterior/transforaminal lumbar interbody fusion. O'Toole and colleagues postulated several possible reasons for the lower risk of SSI associated with minimally invasive surgery: reduced exposure of deep tissue, preventive effect of a tubular retractor for local contamination, smaller incisions, and reduced dead space in the surgical site after closure. ${ }^{26}$ These advantages of minimally invasive techniques can apply to MED, although we were unable to identify the possible reasons for the reduced SSI risk in our study. Further analyses designed to investigate the pathomechanism of the lower invasiveness of MED are warranted.

This study also showed that the average length of hospital stay was significantly shorter for patients undergoing MED than for patients undergoing open discectomy, which was consistent with previous reports. ${ }^{11,14,30}$ However, the average length of hospital stay in the present study (11 days in patients treated via MED) was longer than those in previous reports, which ranged from 1 to 2 days. . $^{3,9,227,32,37}$ According to the Organization for Economic Cooperation and Development Health Statistics 2014, the national average length of hospital stay in Japan was 17.2 days, which was much longer than those in other countries (http:// www.oecd.org/els/health-systems/oecd-health-statistics2014-frequently-requested-data.htm). In Japan, hospitals often provide both early postoperative care and subsequent rehabilitation in a single hospitalization. We believe that the longer hospitalization in the present study can provide more precise information on postoperative comorbidities reflecting surgical invasiveness.

This study has several limitations. First, the study was based on a retrospective observational design, and the treatment assignment was not random. Although measured confounders were adjusted by the propensity score analyses, the results may still be biased by unmeasured confounders. Second, the coded diagnoses may be less accurate than the diagnoses recorded in prospective studies because of possible misclassification or underreporting. However, we believe that the rate of miscoding was relatively low in the DPC database because the attending physicians recorded the diagnoses. Third, the DPC database does not provide detailed clinical information such as the surgeons' technical proficiency, size of disc herniation, detailed surgical procedure (e.g., use of a microscope in open discectomy), and detailed surgery-related complications (e.g., durotomy). Finally, we were unable to obtain data regarding mortality and complications that occurred after discharge; therefore, the long-term mortality and morbidities could not be evaluated.

\section{Conclusions}

The present study suggests that the microendoscopic technique reduces the risk for SSI and major complications following discectomy in patients with lumbar disc herniation. Microendoscopic surgery can be a safer and less invasive procedure than open surgery.

\section{Acknowledgments}

This work was supported by grants for Research on Policy Planning and Evaluation from the Ministry of Health, Labour and Welfare, Japan (grant numbers: H27-Policy-Designated-009 and H27-Policy-Strategy-011).

\section{References}

1. Austin P: Using the standardized difference to compare the prevalence of a binary variable between two groups in observational research. Commun Stat Simul Comput 38:12281234,2009

2. Baba S, Oshima Y, Iwahori T, Takano Y, Inanami H, Koga $\mathrm{H}$ : Microendoscopic posterior decompression for the treatment of thoracic myelopathy caused by ossification of the ligamentum flavum: a technical report. Eur Spine J [epub ahead of print], 2015

3. Brayda-Bruno M, Cinnella P: Posterior endoscopic discectomy (and other procedures). Eur Spine J 9 (Suppl 1):S24$\mathrm{S} 29,2000$

4. Chikuda H, Ohya J, Horiguchi H, Takeshita K, Fushimi K, Tanaka S, et al: Ischemic stroke after cervical spine injury: analysis of 11,005 patients using the Japanese Diagnosis Procedure Combination database. Spine J 14:2275-2280, 2014

5. Chikuda H, Yasunaga H, Horiguchi H, Takeshita K, Kawaguchi $\mathrm{H}$, Matsuda S, et al: Mortality and morbidity in dialysis-dependent patients undergoing spinal surgery: analysis of a national administrative database in Japan. J Bone Joint Surg Am 94:433-438, 2012

6. Chikuda H, Yasunaga H, Horiguchi H, Takeshita K, Sugita S, Taketomi S, et al: Impact of age and comorbidity burden on mortality and major complications in older adults undergoing orthopaedic surgery: an analysis using the Japanese diagnosis procedure combination database. BMC Musculoskelet Disord 14:173, 2013

7. Chikuda H, Yasunaga H, Takeshita K, Horiguchi H, Kawaguchi H, Ohe K, et al: Mortality and morbidity after highdose methylprednisolone treatment in patients with acute cervical spinal cord injury: a propensity-matched analysis using a nationwide administrative database. Emerg Med J 31:201-206, 2014

8. D'Agostino RB Jr: Propensity score methods for bias reduction in the comparison of a treatment to a non-randomized control group. Stat Med 17:2265-2281, 1998

9. Foley KT, Smith MM: Microendoscopic discectomy. Tech Neurosurg 3:301-307, 1997

10. Franzini A, Messina G, Ferroli P, Broggi G: Minimally invasive disc preserving surgery in cervical radiculopathies: the posterior microscopic and endoscopic approach. Acta Neurochir Suppl (Wien) 108:197-201, 2011

11. Garg B, Nagraja UB, Jayaswal A: Microendoscopic versus open discectomy for lumbar disc herniation: a prospective randomised study. J Orthop Surg (Hong Kong) 19:30-34, 2011

12. Hermantin FU, Peters T, Quartararo L, Kambin P: A prospective, randomized study comparing the results of open discectomy with those of video-assisted arthroscopic microdiscectomy. J Bone Joint Surg Am 81:958-965, 1999

13. Huang TJ, Hsu RW, Li YY, Cheng CC: Less systemic cytokine response in patients following microendoscopic versus open lumbar discectomy. J Orthop Res 23:406-411, 2005

14. Hussein M, Abdeldayem A, Mattar MM: Surgical technique and effectiveness of microendoscopic discectomy for large uncontained lumbar disc herniations: a prospective, randomized, controlled study with 8 years of follow-up. Eur Spine J 23:1992-1999, 2014 
15. Lawton CD, Smith ZA, Lam SK, Habib A, Wong RHM, Fessler RG: Clinical outcomes of microendoscopic foraminotomy and decompression in the cervical spine. World Neurosurg 81:422-427, 2014

16. Lee SH, Chung SE, Ahn Y, Kim TH, Park JY, Shin SW: Comparative radiologic evaluation of percutaneous endoscopic lumbar discectomy and open microdiscectomy: a matched cohort analysis. Mt Sinai J Med 73:795-801, 2006

17. Masuda K, Chikuda H, Yasunaga H, Hara N, Horiguchi H, Matsuda S, et al: Factors affecting the occurrence of pulmonary embolism after spinal surgery: data from the national administrative database in Japan. Spine J 12:1029-1034, 2012

18. Matsumoto M, Hasegawa T, Ito M, Aizawa T, Konno S, Yamagata $\mathrm{M}$, et al: Incidence of complications associated with spinal endoscopic surgery: nationwide survey in 2007 by the Committee on Spinal Endoscopic Surgical Skill Qualification of Japanese Orthopaedic Association. J Orthop Sci 15:92-96, 2010

19. Matsumoto M, Watanabe K, Ishii K, Tsuji T, Takaishi H, Nakamura M, et al: Posterior decompression surgery for extraforaminal entrapment of the fifth lumbar spinal nerve at the lumbosacral junction. J Neurosurg Spine 12:72-81, 2010

20. McGirt MJ, Parker SL, Lerner J, Engelhart L, Knight T, Wang MY: Comparative analysis of perioperative surgical site infection after minimally invasive versus open posterior/ transforaminal lumbar interbody fusion: analysis of hospital billing and discharge data from 5170 patients. J Neurosurg Spine 14:771-778, 2011

21. Minamide A, Yoshida M, Yamada H, Hashizume H, Nakagawa Y, Nishi H, et al: Efficacy of posterior segmental decompression surgery for pincer mechanism in cervical spondylotic myelopathy: a retrospective case-controlled study using propensity score matching. Spine (Phila Pa 1976) 40:1807-1815, 2015

22. Minamide A, Yoshida M, Yamada H, Nakagawa Y, Maio $\mathrm{K}$, Kawai M, et al: Clinical outcomes of microendoscopic decompression surgery for cervical myelopathy. Eur Spine J 19:487-493, 2010

23. Muramatsu K, Hachiya Y, Morita C: Postoperative magnetic resonance imaging of lumbar disc herniation: comparison of microendoscopic discectomy and Love's method. Spine (Phila Pa 1976) 26:1599-1605, 2001

24. Ohya J, Chikuda H, Kato S, Horiguchi H, Takeshita K, Tanaka S, et al: Risks of in-hospital death and complications after fusion surgery in patients with atlantoaxial subluxation: analysis of 1090 patients using the Japanese Diagnosis Procedure Combination database. World Neurosurg 83:603-607, 2015

25. Oshima Y, Takeshita K, Inanami H, Takano Y, Koga H, Iwahori $\mathrm{T}$, et al: Cervical microendoscopic interlaminar decompression through a midline approach in patients with cervical myelopathy: a technical note. J Neurol Surg A Cent Eur Neurosurg 75:474-478, 2014

26. O'Toole JE, Eichholz KM, Fessler RG: Surgical site infection rates after minimally invasive spinal surgery. J Neurosurg Spine 11:471-476, 2009

27. Palmer S: Use of a tubular retractor system in microscopic lumbar discectomy: 1 year prospective results in 135 patients. Neurosurg Focus 13(2):E5, 2002

28. Parker SL, Adogwa O, Witham TF, Aaronson OS, Cheng J, McGirt MJ: Post-operative infection after minimally invasive versus open transforaminal lumbar interbody fusion (TLIF): literature review and cost analysis. Minim Invasive Neurosurg 54:33-37, 2011

29. Quan H, Sundararajan V, Halfon P, Fong A, Burnand B, Luthi JC, et al: Coding algorithms for defining comorbidities in ICD-9-CM and ICD-10 administrative data. Med Care 43:1130-1139, 2005
30. Righesso O, Falavigna A, Avanzi O: Comparison of open discectomy with microendoscopic discectomy in lumbar disc herniations: results of a randomized controlled trial. Neurosurgery 61:545-549, 2007

31. Roh SW, Kim DH, Cardoso AC, Fessler RG: Endoscopic foraminotomy using MED system in cadaveric specimens. Spine (Phila Pa 1976) 25:260-264, 2000

32. Ruetten S, Komp M, Merk H, Godolias G: Full-endoscopic interlaminar and transforaminal lumbar discectomy versus conventional microsurgical technique: a prospective, randomized, controlled study. Spine (Phila Pa 1976) 33:931939, 2008

33. Ruetten S, Komp M, Merk H, Godolias G: Recurrent lumbar disc herniation after conventional discectomy: a prospective, randomized study comparing full-endoscopic interlaminar and transforaminal versus microsurgical revision. J Spinal Disord Tech 22:122-129, 2009

34. Sasaoka R, Nakamura H, Konishi S, Nagayama R, Suzuki E, Terai H, et al: Objective assessment of reduced invasiveness in MED. Compared with conventional one-level laminotomy. Eur Spine J 15:577-582, 2006

35. Schick U, Döhnert J, Richter A, König A, Vitzthum HE: Microendoscopic lumbar discectomy versus open surgery: an intraoperative EMG study. Eur Spine J 11:20-26, 2002

36. Schizas C, Tsiridis E, Saksena J: Microendoscopic discectomy compared with standard microsurgical discectomy for treatment of uncontained or large contained disc herniations. Neurosurgery 57 (4 Suppl):357-360, 2005

37. Shin DA, Kim KN, Shin HC, Yoon DH: The efficacy of microendoscopic discectomy in reducing iatrogenic muscle injury. J Neurosurg Spine 8:39-43, 2008

38. Shousha M, Cirovic D, Boehm H: Infection rate after minimally invasive noninstrumented spinal surgery based on 4350 procedures. Spine (Phila Pa 1976) 40:201-205, 2015

39. Teli M, Lovi A, Brayda-Bruno M, Zagra A, Corriero A, Giudici F, et al: Higher risk of dural tears and recurrent herniation with lumbar micro-endoscopic discectomy. Eur Spine J 19:443-450, 2010

40. Wu X, Zhuang S, Mao Z, Chen H: Microendoscopic discectomy for lumbar disc herniation: surgical technique and outcome in 873 consecutive cases. Spine (Phila Pa 1976) 31:2689-2694, 2006

41. Yamada H, Yoshida M, Hashizume H, Minamide A, Nakagawa Y, Kawai M, et al: Efficacy of novel minimally invasive surgery using spinal microendoscope for treating extraforaminal stenosis at the lumbosacral junction. J Spinal Disord Tech 25:268-276, 2012

\section{Disclosures}

The authors report no conflict of interest concerning the materials or methods used in this study or the findings specified in this paper.

\section{Author Contributions}

Conception and design: Ohya. Acquisition of data: Ohya, Oichi, Matsui, Fushimi. Analysis and interpretation of data: Ohya, Yasunaga. Drafting the article: Ohya. Critically revising the article: Oshima, Chikuda. Reviewed submitted version of manuscript: Chikuda, Tanaka. Statistical analysis: Ohya, Yasunaga. Administrative/technical/material support: Matsui, Fushimi, Yasunaga. Study supervision: Tanaka.

\section{Correspondence}

Junichi Ohya, Department of Orthopaedic Surgery, Faculty of Medicine, The University of Tokyo, 7-3-1 Hongo, Bunkyo-ku, Tokyo 113-0033, Japan. email: oyaj-ort@h.u-tokyo.ac.jp. 